\title{
População de Rua, Território e gestão de políticas sociais: para além de um retrato social
}

\author{
Street Population, Territory and management of social policies: beyond a social \\ portrait
}

Mariana Sato dos Reis*

Maria Luiza Amaral Rizzotti**

\begin{abstract}
Resumo:
O presente artigo discute sobre a população em situação de rua e a sua interação com o território. $O$ território é retratado enquanto o chão das políticas sociais e visto além do olhar geográfico. Para uma melhor compreensão do fenômeno população em situação de rua é necessário apreender as múltiplas determinações que constituem essa situação, bem como acompanhar o movimento histórico, político e econômicosocial da realidade que está em constante transformação. Assim, a compreensão dos "espaços vazios" ocupados por essa população, torna-se um grande desafio tanto para as políticas sociais quanto para os profissionais que trabalham com esse segmento. Além disso, o presente estudo aborda a apropriação da lógica territorial na gestão de política social com o objetivo de construir uma reflexão que associe a complexidade do cotidiano da população de rua, sobretudo, quando dirige o olhar para o território e o caminho a ser trilhado na gestão das políticas sociais com essa mesma perspectiva. ${ }^{1}$
\end{abstract}

Palavras-chave: População em situação de rua. Território. Espaços vazios. Política pública. Gestão de políticas sociais.

\begin{abstract}
:
This article discusses about the homeless population and its interaction with the territory. This is portrayed as the ground of social policies and it's locked beyond the geographical point. For a better understanding of the phenomenon homeless population is necessary to grasp the multiple determinations that constitute this situation and monitor the movement of history, political and social-economic reality that is constantly changing. Thus, understanding the "empty spaces" occupied by this population, it becomes a great challenge for social policy and for professionals working with this segment. Furthermore, this study addresses the appropriation of territorial
\end{abstract}

\footnotetext{
* Mestranda do Programa de Pós-Graduação em Serviço Social e Política Social da Universidade Estadual de Londrina - UEL marianareis ss@yahoo.com.br

** Profa. Dra. do Departamento de Serviço Social da Universidade Estadual de Londrina (UEL). Profa. Dra. do Programa de Pós-Graduação em Serviço Social e Política Social da UEL. marialuizarizzotti@gmail.com

10 presente artigo resulta de dois estudos realizados pelas autoras e apresentados em eventos de pesquisa em âmbito nacional (ENPESS e I SEMINÁRIO NACIONAL DE GESTÃO DE POLÍTICAS SOCIAIS E TERRITÓRIO), salientase que no que concerne ao estudo de gestão é resultante de um estudo das autoras em parceria com as doutorandas Ana Patrícia Pires Nalessso e Andréia Cristina da Silva Almeida.
} 
logic in the management of social policy with the goal of building a reflection involving the complexity of everyday life of the homeless, especially when directed his gaze to the territory and the route to be followed in management of social policies with the same perspective.

Keywords: Homeless population. Territory. Empty spaces. Public policy. Management of social policies.

\section{Introdução}

A população em situação de rua compõe o cenário social de inúmeras cidades do país, e como uma fotografia, retrata o que há de mais desigual e indiferente na sociedade capitalista. Esta população ocupa e interage de diferentes formas nos diferentes lugares que vão constituindo os territórios das cidades. No entanto, um olhar mais atento para a dinâmica social dessa população permitirá observar que, na verdade, ela faz parte não apenas de um retrato, mas de um filme em constante movimento, fruto da própria realidade que por não ser estática, deve ser analisada em suas múltiplas determinações em busca da compreensão de sua totalidade social.

Este artigo tem por objetivo refletir sobre a relação da população em situação de rua e o território, mediada pela necessária atenção que as políticas sociais devem dispensar ao seu contexto. No entanto, esse tema torna-se mais presente quando o alvo de atenção são grupos e famílias devidamente radicados em determinado lugar. Assim, a grande maioria dos documentos oficiais trata o território como o espaço geográfico que define as fronteiras de sua área de abrangência.

Como o objetivo já enunciado acima trata da relação com a gestão, coube uma reflexão sobre premência de aprofundamento da leitura socioterritorial na gestão das políticas sociais, tendo como foco a reflexão de aspectos que implicam em dois importantes processos de gestão.

A especificidade deste estudo reside no fato de relacionar território à proteção de sujeitos que não têm a mesma referência de pertencimento à determinada comunidade, ao mesmo tempo em que seu pertencimento a lugares no espaço urbano não é reconhecido e, muito menos, identificado pelos operadores das políticas sociais. 
O tema nos leva a aprofundá-lo a partir de duas dimensões diferentes. São elas: a condição de pobreza que expulsam cidadãos dos territórios e espaços de convívio, tornando-os aparentemente "sem lugar", ao mesmo tempo em que ocupam espaços urbanos públicos como sendo um território particular. Outro ponto, devidamente articulado com o primeiro diz respeito à maneira pela qual o modo capitalista de produção define a ocupação dos espaços urbanos e delineia o lugar dos "invisíveis" e "sem lugar".

Para tanto, num primeiro momento, aponta-se a visão de território que norteia esta reflexão e em seguida o cenário da população de rua no Brasil. Esta análise estabelece uma intrínseca relação entre os sujeitos e o urbano, que traz em sua circunscrição o desenho do modelo de desenvolvimento econômico, político e social do Brasil, que também se desenha pela intervenção estatal.

Numa relação dialética e articulada aos dramas consequentes do desemprego, perda de vínculos e de um processo de desfiliação como diria Castel (2008), a população de rua expressa e se mantém influenciada das mesmas determinantes geradas tanto pelo processo produtivo, quanto pela desproteção do Estado. Com isso, essa população também divide e desenha o traçado urbano, habitando um território que não a identifica, que mescla o público e o privado e que estabelece uma sociabilidade demarcada pela presença ou "invisibilidade" do território.

Os conteúdos referentes à apropriação da gestão de política social e território ocupam o terceiro ponto deste estudo e traz a preocupação de apontar a difícil trajetória de ampliar a visão do indivíduo para o coletivo, mediada pela leitura socioterritorial. Para tanto, o foco recaiu sobre o aprimoramento dessa leitura nos processos de gestão, assim constituídos, e, sobretudo, do diagnóstico e do planejamento. Neste caso, o caminho analítico buscará demonstrar a relevância da demarcação conceitual do território para o desenvolvimento dos processos citados, considerando as dimensões da leitura socioterritorial vinculada aos determinantes estruturais, históricos e conjunturais e a exigência desse modelo diagnóstico na proposição de planejamentos e planos de ação.

\section{População de rua e território}


De acordo com Koga (2011, p. 33), o território pode ser visto como o "chão concreto das políticas", nele as desigualdades sociais tornam-se evidentes entre os cidadãos. Um mesmo território, sob olhares diferentes, ganha também significados e valores diferentes.

O território, como afirma Santos (2000, p. 22), “[...] só se torna um conceito utilizável para a análise social quando o consideramos a partir do seu uso, a partir do momento em que o pensamos juntamente com aqueles atores que dele se utilizam". A apropriação do território está, dessa forma, intrinsecamente ligada aos significados que os homens vão criando e recriando em torno desse mesmo território em sua vida cotidiana. (KOGA, 2011).

Esse é o ponto central para se analisar a questão do território vinculada ao fenômeno população em situação de rua. Os dados do I Censo e Pesquisa Nacional sobre População em Situação de $\mathrm{Rua}^{2}$, realizado em 2008, identificou 31.922 pessoas nessa situação no Brasil. Dos entrevistados $46,5 \%$ alegam preferirem dormir nas ruas ao contrário de $43,8 \%$ que manifestaram a preferência por pernoitarem nos albergues. Esse dado demonstra o grande número de pessoas que permanecem nas ruas diariamente, habitando locais públicos como praças, parques, calçadas, em baixo de marquises, além de prédios e depósitos abandonados. (BRASIL, 2008?).

Quase metade da população entrevistada $(48,4 \%)$ está há mais de dois anos dormindo na rua ou em albergues e, cerca de $30 \%$ estão dormindo na rua há mais de cinco anos. Os processos imigratórios marcaram a realidade das pessoas em situação de rua na primeira metade do século XX. O Censo mostrou que parte considerável dos entrevistados, $45,8 \%$ sempre viveu no município em que moram atualmente e outros $30 \%$ deslocaram-se de um município para outro, dentro mesmo estado. Assim, 76,1\% são originários do mesmo local em que se encontram ou de locais próximos, situados no mesmo estado. As pessoas denominadas de "trecheiros" somaram 11,9\%, e já viveram em seis (6) ou mais cidades.

Vale destacar que esses últimos dados podem evidenciar ou aumento do desemprego, que é o segundo motivo que leva $29,8 \%$ das pessoas a permanecerem em situação de rua. A ida para as ruas ocorre, em primeiro lugar, por problemas de alcoolismo e outras drogas, $35,5 \%$; desemprego aproximadamente vinte e nove por cento $(29,8 \%)$; e

\footnotetext{
2 O I Censo e Pesquisa Nacional sobre a População de Rua foi realizado pelo Instituto Meta e abrangeu 71 cidades brasileiras, sendo que 48 eram municípios com mais de 300 mil habitantes e 23 capitais. São Paulo, Recife, Belo Horizonte e Porto Alegre não entraram na pesquisa, pois já haviam feito ou estavam fazendo pesquisas semelhantes. Foram entrevistados apenas homens e mulheres maiores de 18 anos.
} 
perda dos vínculos familiares, 29,1\%. Para Telles (2006, p. 49) o desemprego prolongado, intermitente ou até mesmo o não-trabalho "[...] redefinem tempos e espaços da experiência social, desfazem ou refazem em outros termos o jogo de referência traçado entre o trabalho e a moradia e pautam ritmos cotidianos e tempos sociais".

Em busca da sobrevivência, essa população se adapta como pode nas cidades (inclusive trabalhando ou arrumando bicos em busca de renda), e vão fazendo das ruas e espaços públicos, um lugar privado.

Como relata Bauman (2001, p. 121-122), as cidades são formadas por vários "espaços vazios", que são assim denominados, pois o vazio do lugar, de acordo com o autor, "[...] está no olho de quem vê, e nas pernas ou rodas de quem anda. Vazio são os lugares em que não se entra e onde se sentiria perdido ou vulnerável, surpreendido e um tanto atemorizado pela presença de humanos". Tais espaços são muitas vezes ocupados pela população em situação de rua e evitados por muitas pessoas que possuem em suas cabeças um "mapa" cheio de "espaços vazios" inabitados.

Longe de ressaltar a naturalização da vivência de rua, o que se quer retratar é que o "estar" nas ruas, e o permanecer nessa condição, vai muito além do "querer ficar nas ruas". A ausência de vínculos familiares, seja pela morte de um parente querido, seja pelo uso de drogas ou pela questão do desemprego, seja pela separação conjugal, seja por outros tipos de conflitos familiares ou desastres naturais (enchentes, por exemplo) indica que, às vezes, a rua se torna a única ou a última estratégia de sobrevivência.

O que para muitos são apenas "espaços vazios", para essa população se torna o refúgio e o lugar que se criam vínculos, sendo possível a construção de uma identidade. De acordo com Cuchc (2007, p. 177), a identidade social de um indivíduo é definida como o “[...] conjunto de suas vinculações em um sistema social: vinculação de uma classe sexual, uma classe de idade, a uma classe social, a uma nação, etc." Para o autor, a identidade "permite que o indivíduo se localize em sistema social e seja localizado socialmente". Ela é ao mesmo tempo, inclusão e exclusão, uma vez que o indivíduo se identifica a um determinado grupo, distinguindo-se de outros.

Ao criar uma identidade com a rua (muitas vezes involuntariamente, devido às condições materiais em que essa população se encontra) e perder sua identidade primeira, 
fruto de relações e construções sociais anteriores, a população em situação de rua está sujeita ao estigma e ao preconceito que o "estar em situação de rua" Ihes impõem.

Sobre essa questão do estigma e do preconceito que a população em situação de rua sofre, Santos (2010, p. 140), utiliza um termo norte-americano NIMBY (Not in My BackYard, cuja tradução para o português é "Não no meu quintal") como expressão primeira da reação da sociedade frente ao encontro com essa população em seu cotidiano. A autora aponta que é uma reação de discriminação contra o corpo, a aparência física, a forma de se vestir, além do próprio local onde esta população está vivendo.

Como evidencia Escorel (1999, p. 89), nesse encontro, ocorre uma "convivência urbana pautada pelo 'evitar olhar', ou não mostrar que percebeu a presença”. A população em situação de rua torna-se artifício ou confunde-se com a própria cena urbana, já naturalizada e esvaziada de significado e vida.

Este é considerado um território inabitado, cheio de "espaços vazios", entretanto, que não deixa de compor o todo de um complexo territorial maior que faz parte dos bairros e da cidade em si. Por isso deve ser analisado atentamente e reconhecido como um lugar que tem vida, pois visto do chão, pelo olhar da própria população em situação de rua, revela um modo de olhar diferenciado para o meio urbanístico que está ao redor.

Entretanto, os impactos que esse tipo de reação (preconceituosa e estigmatizada) causa, reflete também a crescente higienização que tem ocorrido nas cidades dos diversos estados do país, principalmente nos grandes centros urbanos, devido ao planejamento dos Mega-Eventos (Copa do Mundo de 2014, Olimpíadas 2016) e ao monopólio do mercado imobiliário que está em pleno crescimento. Fato que também provoca a intensificação de ações violentas contra as pessoas em situação de rua que, além de serem injustificadas, na grande maioria das vezes, não são punidas.

Nos dias 19 a 21 de março de 2012 foi realizado na Bahia o I Congresso do Movimento Nacional da População de Rua (CONSELHO FEDERAL DE SERVIÇO SOCIAL, (2012), cujo tema central era: "Protagonizando histórias e garantindo direitos". Um dos assuntos abordados no evento foi a questão da violência e do preconceito que essa população sofre diariamente nas ruas. O Centro Nacional de Defesa dos Direitos Humanos da População em Situação de Rua e dos Catadores (CNDDH) divulgou que 165 pessoas em situação de rua haviam sido mortas de abril de 2011 até março do ano de 2012. 
Dessa forma, fica evidente que quando os "espaços vazios", diariamente ignorados pelas pessoas que circulam nas cidades, são percebidos, essa percepção muitas vezes ocorre apenas pela repulsa do que os olhos enxergam e, o incômodo causado pela imagem vista pode provocar reações violentas e bárbaras, como as que têm acontecido nos últimos anos contra essa população.

Outro ponto que merece atenção sobre a relação da população em situação de rua e o território habitado é o aumento do número de refugiados em situação de rua no país. A crise instaurada nos Estados Unidos desde 2008, e os consequentes impactos que ela causou nas economias, principalmente as européias, tem ocasionado a migração de pessoas de várias partes do mundo para ao Brasil. Além da crise, as novas crises humanitárias (os refugiados são da Síria, Costa do Marfim, Mali e República Democrática do (ongo $)^{3}$, aliada aos antigos conflitos (principalmente na África e Oriente Médio), continuam provocando deslocamentos.

De acordo com os dados do Comitê Nacional para Refugiados (CONARE), o número de estrangeiros que solicitam refúgio no país em 2012 em relação a 2010. Em 2012, 2.008 pessoas pediram refúgio no ano passado, sendo que em 2010 foram apenas 566 solicitações (um aumento de 254\%). Para 2013, o CONARE estima que serão contabilizadas 2.580 novas solicitações (UNITED NATIONS HIGH COMMISSIONER FOR REFUGOES, 2013).

O refúgio é um direito de estrangeiros garantido por uma Convenção da ONU de 1951 e confirmado pela lei brasileira 9.474, de 1997. O refúgio pode ser solicitado por todo estrangeiro que possua fundado temor de perseguição por motivos de raça, religião, opinião pública, nacionalidade ou por pertencer a grupo social específico. E também para pessoas que tenham sido obrigadas a deixar seu país de origem devido a grave e generalizada violação de direitos humanos.

O caso é que muitas dessas pessoas não conseguem a autorização de refúgio para ficar no Brasil, tão logo chegam aqui e, sem trabalho ou qualquer outra forma de renda, acabam permanecendo nas ruas. Esses dados configuram um novo retrato da população em situação de rua no país, dinamizada pelo avanço desenfreado das mudanças que o

\footnotetext{
${ }^{3}$ De acordo com o CONARE, o fluxo de haitianos estancou após a resolução do Ministério da Justiça e do Ministério do Trabalho e Relações Exteriores, em 2012 que orienta sobre uma ação humanitária para os haitianos que deixaram o país após o terremoto em 2010. Até o momento, o CONARE contabiliza 9 mil haitianos regularizados no país (UNITED NATIONS HIGH COMMISSIONER FOR REFUGOES, 2013)
} 
capitalismo vem enfrentando, principalmente aliado a indústria da guerra, financiadora de conflitos étnico-raciais (DELORENZO, 2011).

Como afirma Haesbaert e Porto-Gonçalves (2006, p. 49), nesse mundo sem fronteiras, "[...] a liberdade de fluidez para o capital e as informações não são acompanhadas pela liberdade de deslocamento para as pessoas, especialmente a massa crescente de despossuídos, sem dúvida o 'perigo' mais sério na nova des-ordem mundial".

Para os autores, a migração estimulada pelo avanço da globalização, também pode ser considerada como uma "diáspora" moderna que, parece estar anunciando "[...] uma nova e muito mais complexa (multi) territorialidade, na qual convivem os mais diferentes tipos de des-ordenamento territorial [...]". Este fato pode "[...] tanto estimular o diálogo inter ou transcultural como envolver-se em novas formas de preconceito e segregação socioespacial", que é o vem ocorrendo com aqueles que não conseguem a autorização de refúgio para permanecerem em terras brasileiras e, sem terem recursos ou outras alternativas acabam permanecendo nas ruas.

A Política Nacional para Pessoas em Situação de Rua (2009) é uma conquista recente no âmbito da política pública para essa população. Os Centros de Referência Especializados para População em Situação de Rua (Centros POP), previstos nessa Política, dentro da Proteção Social de Média Complexidade, no âmbito da Política Nacional de Assistência Social (PNAS), estão sendo pouco a pouco instalados no país. Um dos eixos norteadores do Serviço Especializado para Pessoas em Situação de Rua é justamente a relação com a cidade e a realidade do Território.

Assim fala a normativa: "É nos espaços públicos da cidade que inúmeras condições locais interagem, influenciam e caracterizam a vida das pessoas em situação de rua. Para a realização do trabalho [...] é importante, portanto, considerar a relação que estabelecem com a cidade e o território". (BRASIL, 2011, p. 73).

A compreensão de suas estratégias de sobrevivência e adaptação, bem como seus costumes e as condições a que estão expostos cotidianamente revela a maneira pela qual se interconectam com aquele território. Também possibilita que a atuação dos profissionais que trabalham com a população em situação de rua, esteja em sintonia com o movimento da realidade, acompanhada da dinâmica territorial que está em constante mudança e reorganização. 
Portanto, acompanhar as transformações ocorridas na realidade social que envolve as pessoas em situação de rua (inclusive as mudanças geradas pela a crise econômica), bem como, a maneira pela qual essas pessoas interagem com o território que ocupam, criando estratégias de sobrevivência e de luta contra a as desigualdades a que estão sujeitas, é fundamental para se pensar o trabalho junto a esta população.

Como afirma Telles (2006, p. 69) os tempos biográficos “[...] organizam trajetórias que individualizam histórias de vida e estão inscritos em práticas situadas em espaços que as colocam em fase com tempos sociais e temporalidades urbanas. "

Como revelou Aristóteles "O que não está em nenhum lugar não existe". No caso da população em situação de rua, os dizeres do filósofo podem ser alterados da seguinte forma: para muitos ela não existe ainda que esteja em algum lugar. O véu que encobre as histórias de vida dessa população precisam ser defeitos e, os preconceitos deixados de lado. Enxergar o meio urbano como essa população enxerga, eis o grande desafio para os profissionais e para as políticas públicas.

\section{De retrato social a sujeitos históricos}

A ontologia marxiana tem como ponto de partida o ser em sua existência objetiva, enquanto parte "movente e movida" de um "complexo concreto". Isso resulta na análise do ser enquanto processo histórico, e em categorias que fundamentam esse ser, e que também são formas "moventes e movidas" da própria matéria, que compõem as formas de existência e as determinações de existência do ser (LUKÁCS, 1968, p. 3).

Marx e Engels (1977, p. 39) explicam que, para poder fazer história os homens devem estar em condições de viver (comer, morar); sendo assim ele define como primeiro "ato histórico" a produção dos meios que permitam a satisfação dessas necessidades.

O processo de desenvolvimento da consciência ocorrerá, desse modo, de forma tardia no movimento da constituição do ser material. No entanto, como alerta Lukács (1968), “[...] para uma filosofia evolutiva materialista, [...] o produto tardio não é jamais necessariamente um produto de menor valor ontológico. "

É a partir do processo de formação da consciência que se apreende a realidade concreta, e, dessa forma, é possível que nela se interfira. Por conseguinte, a existência do ser social (apto ao desenvolvimento da consciência) ocorre pela base do ser orgânico, que 
por sua vez, desenvolve-se pela base de um ser inorgânico (em um movimento que é contínuo, quando não, contraditório).

Para que ocorra a passagem do ser em sua forma mais simples para suas estruturas mais complexas, é necessário que ocorra um salto (ontológico), sem que, no entanto, as formas mais simples do ser sejam desconsideradas, pois compõem a base fundante do mesmo. A constituição do trabalho "[...] enquanto base dinâmico-estruturante de um novo tipo de ser [...]", que só conseguirá se desenvolver a partir de um "[...] determinado grau de desenvolvimento do processo de produção orgânica", como explicita Lukács (1968, p. 4) é mola propulsora desse salto.

Para tanto, o papel da consciência é fundamental. Lukács (1968) em referência a Marx, destaca que o produto do trabalho, nada mais é do que o resultado de um processo que já existia idealmente "[...] na representação do trabalhador". Essa será a diferença fundante entre o ser orgânico e o ser social: o desenvolvimento do processo de formação da consciência. No entanto, quando a mesma não se torna um poder ontológico efetivo, a questão da liberdade que visa a dar respostas às necessidades do ser, jamais poderá se concretizar de forma plena.

É dessa forma que se designa o "homem que trabalha" ou "o animal tornado homem através do trabalho", como um ser que dá respostas. De acordo com Lukács $(1968$, p. 5):

[...] o homem torna-se ser que dá respostas precisamente na medida em que paralelamente ao desenvolvimento social e em proporção crescente - ele generaliza, transformando em perguntas seus próprios carecimentos e suas possibilidades de satisfazê-los; e quando, em sua resposta ao carecimento que a provoca, funda e enriquece a própria atividade com tais mediações, frequentemente bastante articuladas. De modo que, não apenas a resposta, mas também a pergunta é um produto imediato da consciência que guia a atividade; todavia, isso não anula o fato de que o ato de responder é o elemento ontologicamente primário nesse complexo dinâmico.

Sendo assim, o trabalho funda o ser social, na medida em que "[...] converte-se no modelo da forma do ser em seu conjunto". Ele é realizado a partir de posições teleológicas, que condicionam o funcionamento de séries causais que, ao contrário de mera causalidade, são direcionadas por um "pôr teleológico" guiado pela consciência do ser que orienta sua capacidade de intervir na realidade (LUKÁCS, 1968, p. 6). 
Tudo isso aqui explicitado remete à construção da práxis social, cujo caráter em si é ineliminavelmente contraditório. Se, por um lado, a práxis é uma decisão entre alternativas; por outro, a necessidade social só poderá se afirmar através da pressão que exerce sobre os indivíduos, a fim de que suas decisões tenham uma determinada orientação social.

É a partir dessa condição na qual o homem vive em sociedade, geradora dos problemas reais que envolvem o complexo da liberdade. Até que ponto as escolhas dos indivíduos, condicionadas por finalidades sociais específicas, são de fato escolhas livres?

Nesse âmbito, depara-se com a discussão dos valores e do dever-ser, que nada tem a ver com o ser orgânico ou inorgânico, mas com o ser puramente social. É a partir da constituição do "ser-para-nós" (meramente pensado, cujo produto do trabalho adquire função social), que aparecem os valores. O mesmo ocorre com o dever-ser, cujo conteúdo direciona o comportamento dos homens a determinadas finalidades sociais.

A partir dessas reflexões iniciais, evidencia-se que o homem enquanto pessoa humana (ser social) deixa sua condição de ser natural, e transforma-se de espécie animal que alcançou certo grau de desenvolvimento para o gênero humano, humanidade. E com a complexificação da sociedade e de suas respectivas estruturas sociais, econômicas, políticas e culturais, a forma de produção e reprodução da vida material também se complexifica. Logo o trabalho e suas relações tornam-se também complexas. Por conta disso as contradições tornam-se cada vez mais elevadas. Nas palavras de Lukács (1968, p. 15):

\footnotetext{
O progresso é decerto uma síntese das atividades humanas, mas não o aperfeiçoamento no sentido de uma teleologia qualquer: por isso, esse desenvolvimento destrói continuamente os resultados primitivos que, embora belos, são economicamente limitados; por isso, o progresso econômico objetivo aparece sempre sob a forma de novos conflitos sociais. É assim que surgem, a partir da comunidade primitiva dos homens, antinomias aparentemente insolúveis, isto é, as oposições de classe; de modo que até mesmo as piores formas de inumanidade são o resultado desse progresso.
}

É a partir desse ponto, das contradições e das desigualdades geradas no avanço e progresso do capitalismo, que se chega à discussão da população em situação de rua. Muitos são os fatores que levam as pessoas a morar e obter sustento nas ruas, fato este que torna sua realidade social algo não homogêneo, mas dinâmico e dialético. 
Sendo assim, para entender a complexidade do universo que envolve as pessoas em situação de rua é necessário que se atente para um olhar ontológico da realidade social, só assim será possível compreender as múltiplas determinações que cercam o cotidiano e a história dessas pessoas. Ir da aparência à essência, do singular ao universal, atentando-se para as particularidades, síntese das diversas mediações que vão sendo construídas e apreendidas.

Nessa dinâmica de análise e compreensão do fenômeno população em situação de rua é possível que se ultrapasse da visão de mero retrato social, componente natural da paisagem urbana, para sujeitos sociais históricos, que são atores e sujeitos desse processo; agentes ativos, e não passivos de suas vidas, que condicionadas por determinantes sociais complexos, essa população, muitas vezes, não é capaz de trazer à tona o "dar conta" de atender as suas necessidades básicas, o que não quer dizer que não interajam com a dinâmica da realidade social e que não empreendam esforços na luta pela sua sobrevivência.

Diante da realidade exposta que destacou a dinâmica e a complexidade da realidade da população de rua, inicia-se, a seguir, a exposição da gestão das políticas sociais sob a égide do território, compreendendo que essa apropriação inova ao analisar proteção e desproteção com foco no coletivo, sob forte influência territorial e, sobretudo, destacar os principais processos de gestão como diagnóstico e planejamento, pois nestes dois momentos é que se evidencia com mais precisão a adoção da perspectiva delineada neste estudo, ou seja, a gestão e o território.

\section{Gestão de política social e território}

Pensar a gestão das políticas sociais sob a lógica territorial, tendo como foco a leitura socioterritorial como nos processos de planificação e avaliação significa intercruzar temas referentes tanto ao conceito de território, que como já mencionado tem diferentes interpretações, quanto recuperar os temas que envolvem a gestão, que tem uma forte conexão com os estudos sobre planejamento em nível local.

Essa discussão pode, portanto, remeter ao estudo das diferentes dimensões e visões do conceito de território que aqui acolhe as linhas interpretativas que o reconhecem para além das dimensões geográficas ou, ainda, sob a égide da divisão das macrorregiões como 
forma facilitadora de promover a dominação. Adota-se aqui uma perspectiva crítica que reconhece na leitura das vulnerabilidades que demandam a proteção do Estado como determinadas a partir das referências econômicas, políticas e sociais cunhadas no modelo de produção capitalista e dos limites dos ideários da socialdemocracia para promover a garantia dos diretos.

Além deste aspecto deve-se considerar como balizador do tema o papel da descentralização das políticas sociais que ganha corpo com o Estatuto das Cidades (lei 10.257/2001). Trata-se naturalmente de uma nova divisão que tenha como pressuposto a complexidade das condições de vida das pessoas que estão cunhadas pelo modo como se dá a intervenção pública, as relações de poder e dos recursos simbólicos. (VITTE, 2009).

Nas palavras de Milton Santos: "a categoria de análise é o território utilizado". Dessa forma, esse autor ainda evidencia:

A partir desse ponto de vista, quando quisermos definir qualquer pedaço do território, devemos levar em conta a interdependência e a inseparabilidade entre a materialidade, que inclui a natureza, e o seu uso, que inclui a ação humana, isto é, o trabalho e a política (SANTOS; SILVEIRA, 2006, p. 247).

A análise da realidade socioterritorial tem como pressuposto a demarcação de forma estruturante pela lógica econômica do capital e, portanto seu chão cotidiano reflete as expressões da questão social. Naturalmente essa relação se torna mais intrínseca quando pensadas as relações do capital com o espaço e todas as suas implicações em torno da valorização e especulação imobiliária.

O legado da desigualdade permaneceu e sua marca na cidade é a crescente segregação socioespacial. A terra urbana teve sua função de mercadoria reforçada, cujo acesso passou a se dar mediante o mecanismo da compra e venda. Cresceu, com isso, a especulação imobiliária. Com a disputa de solo urbano para diversos fins, em especial para fins de moradia. Com a forte especulação, observa-se no espaço urbano o fenômeno dos vazios urbanos, de terras estocadas esperando valorização. Para os trabalhadores e grupos sociais mais vulneráveis, os vazios são obstáculos na realização de sua necessidade básica de moradia. Esses vazios urbanos demonstram o caráter perverso que o urbano assume no capitalismo, caráter esse agravado pelo fato dos investimentos públicos em benfeitorias darem-se prioritariamente nas áreas mais valorizadas (VITTE, 2010, p. 83). 
Em relação ao Estado a autora afirma que este exerce vários papéis: é o consumidor de espaço, proprietário fundiário, promotor imobiliário. Mas o seu principal papel é o de regulador do uso do solo, por meio do zoneamento, do Plano Diretor, código de obras, leis urbanísticas, etc. Outra função importante é a implantação de serviços públicos, cuja oferta é desigual tanta espacial como socialmente. Por seu papel regulador e provedor ele constantemente é alvo de grupos sociais diversos que o pressionam para a conquista de direitos (VITTE, 2010, p. 84).

Enquanto um sistema econômico, o capitalismo busca submeter à sua lógica todos os lugares possíveis e, nesse sentido, é exaustivo na sua espacialização; já o capital elege lugares para sua aplicação e fixação, pousando - do ponto de vista quantitativo e qualitativo - em poucas localidades, as quais passam a ter nos estoques (e nos tipos) de capitais ali incorporados o seu principal elemento de caracterização (MORAES, 2011, p. 17 apud ANDRADE, 2012).

Essa égide do domínio do capital demarcador da realidade local é objeto de abordagem de Milton Santos (2000) com duas importantes vertentes que podem e devem alimentar a reflexão critica do tema aqui engendrado exposto como a relação do global e local na medida em que as transformações de uma economia globalizada não podem ter seus reflexos desprezados numa leitura territorial.

A prática do neoliberalismo acarreta mudanças importantes na utilização do território, tornando esse uso mais seletivo do que antes e punindo, assim, as populações mais pobres, mais isoladas, mais dispersas e mais distantes dos grandes centros e dos centros produtivos (SANTOS; SILVEIRA, 2006, p. 302).

Ao mesmo tempo também alerta o autor sobre a história e especificidades do âmbito local ao tratar das causas e consequências de suas vulnerabilidades. Quando trata especificamente da historicidade, Santos e Silveira (2006) citam aspectos do território que revelam ações passadas e presentes, congeladas nos objetos. A combinação entre as ações presentes e passadas, confere um sentido ao que preexiste.

As configurações territoriais são o conjunto de sistemas naturais, herdados por uma determinada sociedade, e dos sistemas de engenharia, isto é, objetos técnicos e culturais historicamente estabelecidos. As configurações territoriais são apenas condições. Sua atualidade, isto é, sua configuração real, advém das ações realizadas sobre elas. É desse modo que se pode dizer que o espaço é sempre histórico. Sua historicidade deriva da conjunção entre as características 
da materialidade territorial e as características das ações". (SANTOS; SILVEIRA, 2006, p. 247-248).

Já o trato das vulnerabilidades tem aqui relevância dado o contexto do uso da categoria território associada à gestão de política social que se define pela implementação de ações que de forma integrada e consolidada colocam-se com a proposição de garantir proteção social.

O território é o terreno das políticas públicas, onde se concretizam as manifestações da questão social e se criam os tensionamentos e as possibilidades para seu enfrentamento (COUTO et al., 2010). A leitura do território que informa o gestor de política social deve ter seu contorno na relação da contradição de classes e de sua trajetória histórica marcada pelas contradições, portanto jamais a apropriação cognitiva do território poderá concebêlo como homogênio e desprovido do resultado de suas lutas e sua história.

\footnotetext{
O território é assim produto concreto da luta travada pela sociedade no processo de produção de sua existência. [...] Dessa forma, são as relações sociais de produção que dão a configuração histórica específica ao território. Logo o território não é um prius ou um a priori, mas a contínua luta da sociedade pela socialização igualmente contínua da natureza (OLIVEIRA, 2002, p. 74).
}

Muito embora o foco da nossa reflexão ao considerar na leitura socioterritorial as determinações históricas e estruturais próprias do modelo econômico, dois outros aspectos devam ser pensados neste tema. O primeiro diz respeito deste espaço como homogênio de vulnerabilidade o que inviabiliza toda e qualquer consideração de suas potencialidades. Outro aspecto diz respeito à tradução das determinantes globais para as especificidades do cotidiano e da história do local no do qual se vive e se fala.

Neste caminho olhar para os diferentes espaços, territórios que constituem a sociedade se torna relevante à medida que ao particularizar revela as desigualdades existentes, ou seja, em uma sociedade desigual os espaços são ocupados de forma diferentes, os territórios ao serem espacialmente instituídos segundo o interesse do capital, passam a ser distribuídos e significados de formas distintas, as quais reforçam as diferenças de classes. 
O conhecimento do território implica ainda na compreensão de sua dinâmica cotidiana que envolva os tempos para além do horário diurno e comercial que estão em funcionamento os equipamentos públicos de política social.

\footnotetext{
A cidade, como lugar, tem uma dimensão explicativa, e é uma condição de realização da vida cotidiana, vida essa que resulta de uma relação do indivíduo com a própria cidade. Na cidade se dá o processo de produção da vida que tem vínculos com os modos de apropriação do espaço pelos seus habitantes (VITTE, 2010, p. 81).
}

Os textos que, no campo da administração e gestão pública tratam da dimensão territorial o fazem, na maioria das vezes, como o mesmo pressuposto da descentralização, tendo como ponto central a especificação do local e a delimitação geográfica.

Em continuidade à análise que empreendemos resta-nos abordar a relação da lógica territorial com o processo de planejamento de uma dada política pública (como no caso da PNPR, por exemplo) no momento da proposição de novas ações e empreendimentos. Nesta linha, pouco se encontra escrito, mas é possível fazer uma conexão com os pressupostos de planejamentos participativos, dado o fato de que a demarcação territorial, embora não confundida com delimitação espacial, pode trazer convergência entre seus sujeitos assim como a expressão de suas especificidades.

A falta de articulação entre as diferentes políticas que incidem sobre o território se faz uma preocupação do planejamento, e se constitui alvo da leitura sócio territorial. Conhecer as necessidades e os recursos existentes é fundamental, uma vez que, é no espaço do território que o confronto entre necessidade e possibilidade se efetiva.

Partindo deste entendimento é que a territorialização se coloca como instrumento capaz de fortalecer processos democráticos, na medida em que, possibilita, a partir de condições concretas, o conhecimento das diferenças de acesso, das desigualdades, principalmente no que tange ao acesso das políticas e programas pelas pessoas em situação de rua.

As reais demandas dessa população têm como fundamento o conhecimento dos sujeitos e do espaço vivido, considerando as mediações entre os planejadores e os sujeitos que convivem na relação espaço (principalmente da rua, mocós, praças, albergues, 
marquises, etc.), tempo e condições concretas e, ainda capazes de avaliar a capacidade de subversão do cotidiano.

O planejamento deve considerar as possibilidades de participação da população (de rua) nas decisões dos governos, principalmente na criação de novas ações que necessariamente devem estar coadunadas as demandas territoriais, que expressa um cenário heterogêneo.

Nesse sentido Koga e Ramos (2003) salienta que "considerar as diferenças internas de um mesmo território e consequentemente elencar prioridades diferenciadas, seguindo as necessidades de cada população". Ainda, a mesma autora defende que:

\begin{abstract}
O território também representa o chão do exercício da cidadania, pois cidadania significa vida ativa no território, onde se concretizam as relações sociais, as relações de vizinhança e solidariedade, as relações de poder. É no território que as desigualdades sociais tornam-se evidentes entre os cidadãos, as condições de vida entre moradores de uma mesma cidade mostram-se diferenciadas, a presença/ausência dos serviços públicos se faz sentir e a qualidade destes mesmos serviços apresentam-se desiguais (KOGA; RAMOS, 2003, p. 33).
\end{abstract}

É nesse prisma que fundamentamos que o planejamento deve possibilitar a participação da comunidade, e nesse caso específico da própria população em situação de rua, para que tais diferenças sejam elencadas e consideradas no processo de decisão e de controle da qualidade dos serviços públicos.

Baptista (2000) salienta que o "planejamento se realiza a partir de um processo de aproximações, que tem como centro de interesse a situação delimitada como objeto de intervenção" e essas aproximações requerem que o poder de tomada de decisões seja compartilhado entre os atores envolvidos.

É nesse enfoque que salientamos a participação da população em situação de rua (principalmente através do Movimento da População de Rua Nacional e Estaduais) no processo decisório das ações, sendo esta uma das condições fundamentais para o êxito das proposituras para o território.

Cabe colocar que há a partir da década de 1990, a preocupação com a eficiência e eficácia da ação estatal, desta forma o regate do particular poderia somente significar a possibilidade de focalizar as questões mais emergenciais, homogeneizar para permitir intervenções de menor custo e acalmar as tensões sociais. Não é disto que tratamos, mas 
sim da possibilidade que a compreensão do território, das relações existentes neste produzirem um saber capaz de ser socializado entre todos, e neste processo viabilizar objetivações diferentes que contribuam para a busca da diminuição das desigualdades.

Isto seria possível não porque cada território possui diferentes singularidades, mas porque o território é uma construção histórica e, portanto social o que torna possível que no espaço do território se articulem essas singularidades.

Assim, as diferentes estruturas e relações que conformam o território estabelecem uma forma de viver e estar no mundo, como coloca Souza (2010) a complexidade interna dos territórios estabelece "diferenças entre nós e os outros". A apreensão destas diferenças se faz essencial enquanto informações para o planejamento necessário a uma gestão social, o que não significa pautar o espaço da vida privada de cada um (principalmente na dinâmica complexa, que é os "espaços privados" da população em situação de rua), mas possibilitar o diálogo concreto entre a realidade e os sujeitos que dela fazem parte.

\section{Considerações finais}

No presente artigo destacou-se a reflexão da população em situação de rua e o território, mediada pela necessária atenção que as políticas sociais devem dispensar, de forma que acompanhem o movimento concreto da realidade social. Um mesmo território tem inúmeras interpretações e utilidades, visto por ângulos e posições diferentes. O ver das políticas sociais deve acompanhar o ver dos sujeitos que enfrentam a realidade das ruas em seu cotidiano e criam alternativas e estratégias de sobrevivência nos mais variados espaços de uma mesma cidade.

A crise permanente pela qual passa o sistema capitalista tem reflexos diretos no perfil da população em situação de rua, como foi mostrado a partir dos dados do I Censo e Pesquisa Nacional sobre Pessoas em Situação de Rua (2008), que destaca o desemprego como o segundo principal fator de ida para as ruas por parte dessa população. Estar atento a esse movimento que muda também os limites territoriais vinculados à mobilidade humana de um território a outro e de um país a outro em busca de melhores condições de vida, que nem sempre se torna uma realidade possível, é fundamental para apreender as inúmeras condições que cercam a população em situação de rua. 
Essa população, para além de mero retrato social é sujeito histórico e participante ativo dos processos que envolvem o cotidiano dessa história. Ainda que muitas de suas escolhas não sejam livres, mas condicionas por determinantes sociais (que também são partes dos processos históricos), como o uso de drogas, por exemplo, não que dizer que deva ser tratada como retrato letárgico e estacionado no tempo.

A população em situação de rua faz parte de um eterno movimento, de luta contra as de desigualdades sociais, de luta por sobrevivência. Carrega em si uma trajetória de perdas (de vínculos, de emprego, de afeto, de moradia, etc.), de sofrimentos e negação (de direitos, de vínculos, de emprego, de oportunidades, etc.). Mas ela é também possibilidade de reconstrução de vínculos, de escolhas.

Ela retrata a possibilidade de enxergar o movimento da realidade concreta desse sistema, com o que há de mais desigual e desumano. Entretanto, ela carrega em si a possibilidade de esperança, de solidariedade, da construção de estratégias de um viver que ultrapassa as configurações de sociabilidades estratificadas pelo capitalismo, pelo individualismo, pelo "canibalismo" (um ser que devora o outro na perversidade do tempo do capital).

Portanto, conclui-se que o fenômeno população em situação de rua não pode ser analisado desvinculado da perspectiva do território, seja este, enquanto "espaço vazio", seja este enquanto chão das políticas sociais ou enquanto um lugar que reflete as relações sociais que vão sendo construídas e desconstruídas acompanhadas pelas novas configurações do sistema capitalista e do acirramento das desigualdades sociais.

O Centro $\mathrm{Pop}^{4}$ enquanto equipamento específico para o atendimento desta população, no interior da proteção social de média complexidade, no âmbito da Política de Assistência Social (PNAS), traz em sua normativa a importância da análise territorial para que as ações possam ser implementadas e os direitos sociais dessa população possam ser garantidos, evitando-se assim uma homogeneidade nos serviços prestados (BRASIL, 2011).

\footnotetext{
${ }^{4}$ No artigo 70, do Decreto o 7.053 de 23 de dezembro de 2009, está previsto a criação do Centro de Referência Especializado para População em Situação de Rua (Centro POP). Estes Centros pertencem à Proteção Social Especial de Média Complexidade, contida na Política Nacional de Assistência Social (PNAS/2004) do Sistema Único de Assistência Social (SUAS). A Proteção Social Especial de Média Complexidade organiza a oferta de serviços, programas e projetos de caráter especializado que requerem maior estruturação técnica e operativa, com competências e atribuições definidas, destinadas ao atendimento às famílias e aos indivíduos em situação de risco pessoal e social, com direitos ameaçados ou violados (BRASIL, 2011).
} 
De acordo com Koga (2011, p. 354) “Esta lógica desconsidera não somente o conhecimento acumulado do território a respeito de si mesmo, mas também a possibilidade e a própria existência de canais de participação dos cidadãos, antes de tudo, sujeitos de direito."

Além do já exposto, foi traçado um caminho reflexivo neste estudo pautado pela necessidade de aprofundar a importância da lógica territorial na gestão das políticas sociais. Naturalmente alguns conceitos que permeiam este tema, tais como a concepção de território, com diferentes interpretações e foco de diferentes áreas de conhecimento.

Os moradores de um determinado território formam uma identidade coletiva que refletem na condição socioeconômica e em sua cultura. Numa relação dialética, ao mesmo tempo imprimem identidade desse grupo que se apropriam de determinado espaço, vale reforçar que a noção de território associa-se ao regate de histórias, práticas cotidianas. E aliado a isso existe no entremeio, a população em situação de rua, que ocupa esses espaços entre o público e o privado da vida cotidiana.

Aldaíza Sposati (2006, p. 138), ao tratar da relação território numa dimensão mais ampla afirma:

Território não é só a geografia do córrego, do beira-rio ou do morro que desliza. Mais do que isso, é a topografia gerada pelas ações do Estado, do mercado e da sociedade. Topografia de relações culturais, sociais, econômicas e políticas de ocupação de lugares, de distribuições de serviços, de acessos, de viabilidade de viver cotidiano face ao modo de inserção de cada um no processo produtivo.

Consideramos, ainda, que esse recorte deve favorecer os processos de aprimoramento da oferta de políticas sociais, potencializar a condução democrática e a integração da rede de serviços, a partir da visão do desenvolvimento local e da proteção de responsabilidade do Estado, principalmente no que tange ao acesso das pessoas em situação de rua, aos serviços e políticas sociais.

Naturalmente o tema do território traz intrinsecamente a acuidade na proteção, a capacidade das políticas sociais ampliarem seu foco em indivíduos e famílias para grupos populacionais que estabelecem relações circunscritas em territórios, considerando as diferentes realidades, a história, as relações de poder, a estrutura e as dinâmicas próprias, sem desconsiderar o reflexo da estrutura econômica, social e política de dimensões mais amplas que acabam por definir os níveis de desproteção e vulnerabilidade. 
A continuação do estudo aqui iniciado busca identificar as defasagens da abordagem territorial na gestão de políticas sociais em nível municipal, acoplada à lógica da necessidade de apropriação de estratégias e metodologias de leitura socioterritorial e planejamento que permitam um olhar diferenciado e proponham ações que inovem e garantam que esse modelo descentralizado caminhe par e passo com a democratização e desenvolvimento local, com enfoque para os "espaços vazios", que muitas vezes de vazios só possuem o nome.

\section{Referências}

ANDRADE, I. Território e assistência social: uma análise do Serviço Social a partir da produção social do espaço. 2012. Tese (Doutorado em Serviço Social) - Pontifícia Universidade Católica do Rio Grande do Sul, Porto Alegre.

BAPTISTA, M. V. Planejamento social: intencionalidade e instrumentação. 2. ed. São Paulo: Veras, 2000.

BAUMAN, Z. Modernidade líquida. Rio de Janeiro: Zahar, 2001.

BRASIL. Ministério do Desenvolvimento Social e Combate à Fome - MDS. Secretaria de avaliação e Gestão da informação. Meta Instituto de Pesquisa e Opinião. Pesquisa nacional sobre a população em situação de rua. Brasília, 2008.

. Secretaria Nacional de Assistência Social. Secretaria Nacional de Renda e Cidadania. Centro de Referência Especializado para Pessoas em Situação de Rua. Orientações técnicas. Brasília, 2011.

CASTEL, R. Metamorfoses da questão social: uma crônica do solário. Rio de Janeiro: Vozes, 2008.

CONSELHO FEDERAL DE SERVIÇO SOCIAL - CFESS. Em defesa da população em situação de rua. 2012. Disponível em: <http://www.cfess.org.br/visualizar/noticia/cod/759>. Acesso em: 1 mar. 2013.

COUTO, B. R. et al. O Sistema Único de Assistência Social: uma realidade em movimento. São Paulo: Cortez, 2010.

CUCHC, D. Cultura e identidade. In: CUCHC, D. A noção de cultura nas ciências sociais. Bauru: EDUSC, 2007. p. 175-202.

DELORENZO, A. Em busca de um lugar seguro. Revista Fórum, São Paulo, ano 9, n. 98, maio, 2011.

ENGELS, F. MARX, K. A ideologia alemã (Feuerbach). São Paulo: Grijalbo, 1977. 
ESCOREL, S. Vidas ao léu: trajetórias de exclusão social. Rio de Janeiro: Fiocruz, 1999.

HAESBAERT, R.; PORTO-GONÇALVES, C. W. A nova des-ordem mundial. São Paulo: UNESP, 2006.

KOGA, D. Medidas de cidades: entre territórios de vida e territórios vividos. São Paulo: Cortez, 2011.

KOGA, D.; RAMOS, F. Trajetórias de vida: desafios da pesquisa sociourbanística e contribuição para a gestão pública. Revista Serviço Social e Sociedade, São Paulo, n. 16, p. 335-364, abr./jun., 2003.

LUKÁCS, G.; PAULO NETTO, J.; FERNANDES, F. As bases ontológicas do pensamento e da atividade do homem. 1968. Disponível em: <http://webdav.sistemas.pucminas.br:8080/ webdav/sistemas/sga/20082/139876_As\%20bases\%20ontol\%C3\%B3gicas\%20do\%20pens amento\%20e\%20da\%20atividade\%20do\%20homem.pdf>. Acesso em: 2 jul. 2013.

OLIVEIRA, A. A geografia agrária e as transformações territoriais recentes no campo brasileiro. In: CARLOS, A. F. A. (Org.) Novos caminhos da geografia. São Paulo: Contextos, 2002.

SANTOS, M. C. L. dos. Nota sobre a dinâmica socioespacial da população em situação de rua: estratégias de adaptação, sobrevivência e o manejo dos recursos disponíveis no meio urbano. In: CUNHA, J. V. Q.; RODRIGUES, M. (Org.). Rua: aprendendo a contar: pesquisa nacional sobre a população em situação de rua. Brasília: Ministério do Desenvolvimento Social e Combate à Fome, 2010. p. 139-156.

SANTOS, M. Território e sociedade: entrevista com Milton Santos. São Paulo: Fundação Perseu de Abreu, 2000.

SANTOS, M.; SILVEIRA, M. L. O Brasil: território e sociedade no início do século XXI. Rio de Janeiro: Record, 2006.

SPOSATI, A. Gestão pública intersetorial: sim ou não? Comentários de experiência. Serviço Social \& Sociedade, São Paulo, n. 85, p. 133-141, mar. 2006.

TELLES, V. S.; CABANES, R. Nas tramas da cidade: trajetórias urbanas e seus territórios. São Paulo: Humanitas, 2006.

UNITED NATIONS HIGH COMMISSIONER FOR REFUGOES. Alto Comissariado das Nações Unidas para Refugiados (ACNUR). Triplica o número de estrangeiros em busca de refúgio no Brasil. 2013. Disponível em: <http://www.acnur.org/t3/portugues/noticias/noticia/ triplica-o-numero-de-estrangeiros-em-busca-de-refugio-no-brasil/>. Acesso em: 2 jul. 2013.

VITTE, A. C. Modernidade, território e sustentabilidade: refletindo sobre a qualidade de vida. In VITTE, C. C. S.; KEINERT, T. M. M. Qualidade de vida, planejamento e gestão urbana: discussões teórico metodológicas. Rio de Janeiro: Bertrand Brasil, 2009. 
VITTE, C. C. S. Cidadania, qualidade de vida e produção do espaço urbano: desafios para a gestão urbana e para o enfrentamento da questão social. In: BAENINGER, R. (Org.).

População e cidades: subsídios para o planejamento e para as políticas sociais. Brasília: UNFPA, 2010.

Recebido em: 31/09/2013

Aprovado em: $10 / 12 / 2013$ 